\title{
Application of COM-B model as a support to Lean Healthcare diagnostic: the case of Pharmaceutical Care Process
}

Karina Yamashiro Barrionuevo', Istefani Carísio de Paula , Aline Gularte ${ }^{1}$, Lucia Sortica de Bittencourt ${ }^{2}$

${ }^{1}$ Federal University of Rio Grande do Sul - UFRGS, Industrial Engineering Department, Porto Alegre, RS, Brazil.

${ }^{2}$ Postgraduate Program in Pharmaceutical Services - PPGASFAR - UFRGS, Porto Alegre, RS, Brazil.

How to cite: Barrionuevo, K.Y., Paula, I. C., Gularte, A. et al. (2020), "Application of COM-B model as a support to Lean Healthcare diagnostic: the case of Pharmaceutical Care Process", Brazilian Journal of Operations \& Production Management, Vol. 17, No. 3, e20201030. https://doi.org/10.14488/BJOPM.2020.038

\begin{abstract}
Goal: The objective in this paper is to test the Capability, Opportunity, Motivation to perform Behavior model (COM-B model) from the Behavior Change Wheel (BCW) tool (Michie et al., 2014) as part of the diagnosis of Lean Healthcare.

Design / Methodology / Approach: Interviews were performed with health professionals from the Pharmaceutical Care Process (PCPr) in the city of Porto Alegre-RS, responsible for the stages of selection, programming, acquisition, storage, distribution and dispensation (SPASDD) of the PCPr cycle in the municipality. The content analysis of data allowed to develop a model for diagnosing and monitoring the logistical performance of PCPr.

Results: Results indicated that about $94.0 \%$ of problems related to physical and social opportunities in the processes, including improvements in the workspace, furniture, HR hiring and training, security of assets and relationships with users of the PCPr system, which if minimized can reduce the resistance of employees to the change process. Dimensions such as motivation, psychological and physical capacity have revealed lower percentages, but they are important opportunities to improve the PCPr process.

Limitations of the investigation: The reduced number of respondents, however interviews were sufficient to capture the perceptions and build a scenario that may be validated in the future with other stakeholders involved in the process.

Practical implications: The practical contribution resides in the identification of the behaviors to be changed in a Lean Healthcare project at the Pharmaceutical Care context. COM-B helped to identify behaviors that may hamper the efficiency of the PCPr in a large city.
\end{abstract}

Originality I Value: COM-B has proved to be a useful method to support Lean Healthcare projects, the contribution of this investigation lies in expanding the applicability of COM-B model along with Lean Healthcare projects, mainly at the diagnosis stage.

Keywords: Design for Behavior Change; Lean Healthcare; COM-B; BCW; Pharmaceutical Care Process.

\section{INTRODUCTION}

The Lean methodology brings in its core behavioral change, since its objective is to modify the processes to eliminate wastes that do not add value to the costumer, but eliminating such waste largely depends on behavioral changes (Drew et al., 2004; Biazzo and Panizzolo, 2000;

Financial support: None.

Conflict of interest: The authors have no conflict of interest to declare.

Corresponding author: istefanicpaula@gmail.com

Received: 2 July 2020.

Approved: 26 July 2020.

Guest Editors: Fernando Oliveira de Araujo and Chrystyane Abreu. 
Sawhney and Chason, 2005; Emiliani, 1998). This study is based on Lean Healthcare, the Lean concept's field applied to the health area (Graban, 2009).

Since long ago, Herbert Simon (1969) affirmed that design transforms existing situations into favorable situations, and thus, regardless of the area in which it is employed, design influences human behavior by creating desirable or undesirable behaviors, either intentionally or involuntarily. This is reinforced by recent studies. The automobile sector is an example of a behavioral change involuntarily caused by design, as cars objective relied solely upon distance shortening, however, the environmental impact caused by automobiles was an unplanned side effect (Niedderer et al., 2014).

Regarding the intentional human behavior change, IDEO's 'Coasting bike platform' can be highlighted as an example. The 'Coasting bike platform' was a project carried out to change the culture from the majority of the adult population in the United States which did not use bicycles because they were intimidated by the 'lycra-clad' - cultural phenomenon of cycling elitization, in which people wear special clothes and equipment - and the complexity of modern bicycles. This design project rescued the simplicity of cycling to encourage the population to cycle again (Niedderer et al., 2014). The IDEO project documentation did not explicitly refer to behavioral change, although the design was made for that purpose. Thus, this case study represents one of the dilemmas of the design area: considerations about behavioral change, even when intentional, remain implicit.

The genesis of Design for Behavior Change (DFBC) lies in facing this dilemma since DFBC recognizes the ability of design to change people's attitudes on a small or large scale. Based on this, the purpose of DFBC is to manage behavioral changes during the design process (Norman, 1988; Niedderer et al., 2014).

The first study stream that influenced the creation of the DFBC was 'design psychology' or 'behavioral design', a term coined by Don Norman in the 1980's in reference to product design (Norman, 1988). Over time, the evolution of models has been targeted specifically towards behavioral change, as we can derive from the 'emotion design' and 'persuasive technolog' streams. Currently, several theories focus on behavioral change, such as the 'Loughborough model', 'Design with intent', 'Mindful design approaches' among others.

The Behavior Change Wheel (BCW) tool (Michie et al., 2014), which will be addressed in this article, derives from the synthesis of nineteen DFBC models, which were assessed in terms of scope, coherence, and possibility of being implemented in a behavioral model. This combination of models resulted in the BCW, which has three layers: the first represents the center of the wheel (COM-B), the second addresses the intervention functions, and the third encompasses the political categories. To consistently support the two last layers, BCW creators developed the Capability, Opportunity, Motivation to perform Behavior model (COM-B), which serves as a basis for BCW, enabling the transition from behavioral analysis to effective change.

The hypothesis that guides this investigation is that COM-B model may be an adequate instrument to identify inefficient behaviors in Lean Healthcare contexts, serving as support to the choice of people's behaviors to be changed. Thus, the objective is to test COM-B model as a tool to identify behaviors that hamper the efficiency of the Pharmaceutical Care processes in a large city.

The theoretical contribution lies in expanding the applicability of COM-B model along wiht Lean Healthcare projects, mainly at the diagnosis stage. The practical contribution resides in the identification of the behaviors to be changed in a Lean Healthcare project at the Pharmaceutical Care context.

\section{THEORETICAL BACKGROUND}

Two main topics are described in this theoretical background section, namely: Lean Healthcare in pharmaceutical care and the COM-B tool. The first topic addresses the application of Lean Healthcare in an environment with scarce studies, since Lean Healthcare applications are mainly concentrated in the healthcare areas with the highest technological 
density, such as hospitals and clinics. While the COM-B is a tool to identify human behaviors that hamper process efficiency (Michie et al., 2014).

\section{LEAN HEALTHCARE IN PHARMACEUTICAL CARE PROCESS}

Because the Brazilian Constitution guarantees citizens the right to health, the national healthcare system is a complex structure, encompassing the federal, state, and municipal spheres. Thus, municipalities were assigned the responsibility for the healthcare of lower complexity, which has great demand, named Primary Health Care (PHC). The PHC is responsible for the first level of patient contact in with the Unified Health System (SUS), and it is constituted of a set of health actions towards the population of a defined territory including disease prevention, solving possible cases of injuries and directing the most serious to higher levels of care in complexity. Therefore, PHC works as a filter capable of organizing the flow of services in health networks, from the simplest to the most complex. Among these health actions, medicines stand out both for their role in the treatment and in the care process, as well as for their increasing costs due to the aging population and judicialization of the health sector.

Pharmaceutical Care Process (PCPr), also named as Pharmaceutical Care Cycle or Pharmaceutical Services, manages all medicine-related processes, including research, development, and production of medicines and supplies, as well as their selection, programming, acquisition, storage, distribution, and dispensing. In addition to all these functions, PCPr is also responsible for ensuring the quality of products and services, monitoring and evaluating their use to obtain concrete results and to improve the quality of life of the population (Brazil, 2014).

The logistics support of PCPr refers to the processes related to access, care, and the rational use of medicines, targeting the effectiveness and optimization of health actions, as well as the mitigation of risks related to pharmacotherapy. The focus of this article is on the logistical operations for the selection, programming, acquisition, storage, distribution, and dispensing of medicines (SPASDD) and on process optimization, hereafter referred to as "PCPr logistic services".

Regarding PCPr logistic services, the drug dispensing step in the city of Porto Alegre-RS occurs through District Pharmacies, which supply the basic medicines to the population. Such medicines are intended to meet the needs of Primary Health Care complexity level. District pharmacies are located in different regions of the city, and all of them employ pharmacists who act as responsible technicians and service coordinators of medical supplies.

Studies highlight problems related to PCPr management in Brazilian cities (Costa et al., 2017; Furukawa et al., 2016). Thus, Lean Healthcare methodology could provide an alternative to more efficient management focusing on quality increase and waste reduction by identifying and eliminating losses.

As the project's emphasis is on the operational quality of PCPr's logistics services, we aimed at developing a model capable of analyzing physical and information flows, and of monitoring operation's performance under the Lean Healthcare principles. Thus, we sought to identify points of waste and inefficiency, proposing improvements that add value, efficiency, and safety to the processes.

\section{COM-B MODEL}

The Capability, Opportunity, Motivation to perform Behavior model (COM-B) lies in the core of the three-phase tool of Behavior Change Wheel (BCW), as shown in Figure 1. COM-B proposes that people need Capacity $(C)$, opportunity $(\mathrm{O})$, and motivation $(\mathrm{M})$ to perform a behavior (B). Thus, the tool helps understanding behavior within a specific context, identifying behavioral targets to serve as a starting point for change management (Barker et al., 2016).

According to this model, for individuals to perform certain behavior (B) at a given moment, they must be physically and psychologically capable $(C)$ and there must be social and 
physical opportunities $(\mathrm{O})$ for them to perform the expected behavior. Also, individuals must want or need to perform the behavior more than they want or need to perform other competing behaviors at the moment (M). Motivation (M) is related to basic needs and automatic processes like habits and impulses, as well as to reflective processes like intention and choice.

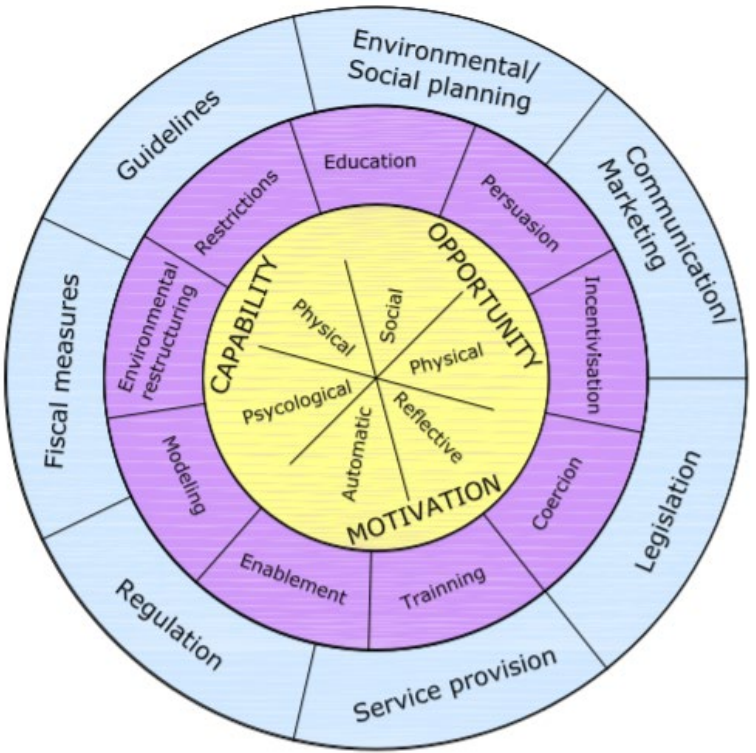

Sources of Behavior

Intervention Functions

Policy Categories

Figure 1 - The behavior change wheel. Source: Adapted from Michie et al. (2014)

Thus, if the desired behavior is not being performed or if an unwanted behavior is being performed, an analysis of the behavioral determinants will help to define what needs to be changed for the desired behavior to occur or for the unwanted behavior to stop being performed.

After the behavioral analysis is conducted through COM-B, we follow to the second level of the BCW wheel, which is composed of nine intervention functions, namely: education, persuasion, incentivization, coercion, training, enablement, modeling, environmental restructuring, and restrictions. Once the intervention functions have been defined, we move to the last level of the BCW wheel, which consists of seven political categories: Legislation, Communication/Marketing, Environment/Social Planning; Guidelines, Fiscal measures, Regulation, Service provision.

After the intervention functions and the case-relevant political categories have been selected, the application of the tool's levels ends. Therefore, the specific behavioral change techniques found in the BCW guide must be followed (Michie et al., 2014). BCW's differential lies in its systematic and transparent way of identifying behavioral issues, intervention functions, and political categories that can lead to the desired changes, in addition to enabling a diagnosis of the success or failure of the change implementation.

Regarding its application, BCW was used to understand and manage changes in clinical practice in several activities, among them: analysis of the techniques used by general practitioners to assess cardiovascular risk; improvements in pediatric services in Kenyan hospitals; implementation of evidence-based guidelines for premature babies and women with postpartum depression (Michie et al., 2016).

The feasibility of COM-B and BCW models was evidenced in the article of Barker et al. (2016) which uses the COM-B and BCW behavioral models to develop an intervention to increase the use of hearing aid in the rehabilitation of adults with hearing loss. The first intervention step was to define the problem under behavioral terms. Although evidence indicated that the hearing aid could mitigate the negative consequences of hearing loss, the 
'Action on Hearing Loss' charity organization estimated that only 1.4 million used it regularly, out of the 2 million people in the UK that were instructed to use a hearing aid. Still, other studies pointed out that the lack of use of the device varied from 5 to $40 \%$. Thus, the desired change would be the regular, long-term use of the hearing aid by adults with hearing loss.

Following the BCW methodology, the second step adopted by Barker et al. (2016) was the selection of behaviors that could lead to the desired change. In the case of the hearing aid, studies indicated that the patient's conduct partially depended on the behavior of a wide variety of people, including health professionals. Thus, the authors decided to focus on the relationship between the patient and health professionals.

The third step involved specifying both the people who would be part of the process and the behaviors that should be performed. Thus the answers to the following questions defined the tasks to be performed: what precisely should be done differently? How and when should it be done? How often should it be done?

The analysis of these three steps concluded that the desired behavior (the B of the COM-B tool) is 'self-management support' (SMS), which means helping people to develop the knowledge and skills necessary to better deal with hearing loss. According to the article, for SMS to be effective, it should be planned and executed collaboratively with professionals.

Finally, the fourth step was the application of COM-B to analyze whether the speech therapists (intervention target public) had the capability, opportunity, and motivation to permanently adopt the new conduct that would lead to the desired changes, that is, the planning and execution of SMS in a collaborative way.

Thus, the aforementioned article used COM-B to investigate the existing capability, opportunity, and motivation limitations that prevent speech therapists from committing to SMS planning. The content of the interviews was grouped into the Capability, Opportunity, and Motivation categories, as shown in Chart 1.

Chart 1 - Interviews' content grouped by categories

\begin{tabular}{|c|c|c|}
\hline & Physical & $\begin{array}{c}\text { Speech therapists do not report difficulties regarding SMS } \\
\text { planning. }\end{array}$ \\
\hline Capability & Psychological & $\begin{array}{l}\text { Knowledge of the potential benefits of SMS for both speech } \\
\text { therapists and patients would be an important motivator. } \\
\text { Planning lessons would be important, as speech therapists could } \\
\text { gain speed and fluidity when planning. } \\
\text { Flexibility was also cited as an important competence, since SMS } \\
\text { planning is individualized, and it should be designed based on the } \\
\text { needs of each patient. } \\
\text { Mental fatigue was identified as a barrier to SMS fulfillment. }\end{array}$ \\
\hline Opportunity & $\begin{array}{l}\text { Physical and } \\
\text { Social }\end{array}$ & $\begin{array}{l}\text { Both physical and social opportunities were reported as } \\
\text { important. } \\
\text { Nine out of ten speech therapists considered the reduced time of } \\
\text { appointments as a barrier to SMS, as they perceive the } \\
\text { appointment duration to be insufficient to conduct basic } \\
\text { procedures (real-ear measurement, explaining how to use the } \\
\text { hearing aid, batteries, and controls). } \\
\text { Participants stated that if SMS planning were perceived as a group } \\
\text { task or as a culture in which everyone implemented the plan } \\
\text { together, it would be more easily assimilated. }\end{array}$ \\
\hline \multirow{2}{*}{ Motivation } & Automatic & $\begin{array}{l}\text { Automatic motivation, which involves emotional reactions, desires, } \\
\text { impulses, habits, and reflex responses, is achieved through speech } \\
\text { therapists and the patients' desire to see positive effects or the } \\
\text { desire to avoid negative consequences to the patient. }\end{array}$ \\
\hline & Reflective & $\begin{array}{l}\text { The procedures that speech therapists find useless are not } \\
\text { performed when they have little time or such procedures are } \\
\text { performed very quickly. This highlights the importance of } \\
\text { convincing speech therapists about the benefits of SMS. }\end{array}$ \\
\hline
\end{tabular}

Source: the authors themselves. 
The conclusions from this reference article point out that COM-B is an effective model to identify the behaviors that must be adjusted to achieve the desired result. In addition, COM-B supports the continuity of the intervention since the subsequent stages of development and evaluation are based on the outcome of such analysis.

In this study, COM-B is applied to Pharmaceutical Care, the first three steps of BCW were not conducted to identify the behavior to be changed, since other practices from Lean Healthcare were used with the same purpose. Thus, the focus of this article is to directly apply COM-B both to identify and to deal with the behavioral issues to be faced.

\section{METHOD}

\section{Research method}

This paper is of qualitative approach based on interviews with the employees of the Pharmaceutical Care Process of the city of Porto Alegre.

\section{Unit of analysis}

This article is based on the project 'Model for diagnosis and monitoring of the logistics performance of the Pharmaceutical Care Process from the perspective of the District Pharmacies professionals of Porto Alegre' developed by a team of researchers from the Industrial Engineering faculty at UFRGS. The research was developed in the city of Porto Alegre which has a population of approximately 1.5 million people (Instituto Brasileiro de Geografia e Estatística, 2018). In the context of the Unified Health System (SUS), the city of Porto Alegre purchases medicines for free distribution to the population. The purchased medicines are stored at the Pharmaceutical Supply Center (CAF) and are subsequently distributed to 10 District Pharmacies (DP) and 139 Health Units, where citizens can collect the medicines. This entire process is managed by the Pharmaceutical Care Process Coordination (COORAF) and has direct participation of pharmaceutical professionals at various points of the process, from the most operational part in the District Pharmacies, to the managerial and strategic processes conducted by COORAF.

\section{Research procedures}

PCPr involves a set of medicine-related procedures, which includes the entire logistical handling and the promotion of the rational use of medicines. To deliver the desired value to health system users, the PCPr network consists of several actors interacting to perform a set of functions, called selection, programming, acquisition, storage, distribution, and dispensing of medicines (SPASDD). Thus, for data collection, we conducted interviews with representatives of the commissions that carry out the PCPr cycle functions: Therapeutic Pharmacy Commission - CFT (responsible for Selection), Commission for the Evaluation of Medicines in Bidding Process - COMEL (responsible for Programming, and Acquisition), Pharmaceutical Supply Center - CAF (responsible for storage and distribution) and District Pharmacies - DP (responsible for the dispensing of medicines to patients).

The interviews were carried out from October to December 2018. For interview accomplishment, a script of questions was designed aiming at identifying the main factors that may lead to poor performance in the tasks of each commission or center. The script contains: (i) a block of questions that describe the interviewee's characteristics; (ii) a block with a description of the tasks performed at the commission or center; (iii) presentation of a card containing the COM-B dimensions (Figure 2). Card presentation was always followed by a question about the factors that can lead to poor task performance considering those dimensions. 


\begin{tabular}{|c|c|c|c|c|c|}
\hline \multirow[t]{2}{*}{ Task \# } & \multicolumn{5}{|c|}{ Factors that lead to poor performance } \\
\hline & $\begin{array}{l}\text { Physical/ } \\
\text { technical } \\
\text { aspects of } \\
\text { the } \\
\text { individual } \\
\text { that } \\
\text { executes } \\
\text { the task } \\
\text { (cognitive, } \\
\text { physiologica } \\
\text { l, training } \\
\text { and } \\
\text { knowledge) }\end{array}$ & 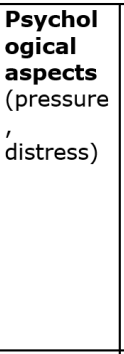 & $\begin{array}{l}\text { Work } \\
\text { environmen } \\
\mathbf{t} \text { aspects - } \\
\text { physical } \\
\text { (equipment } \\
\text { and } \\
\text { infrastructure } \\
\text { ) and social } \\
\text { (interpersonal } \\
\text { relationship, } \\
\text { collaboration) }\end{array}$ & \begin{tabular}{|l|} 
Motivational \\
aspects - \\
what \\
motivates or \\
demotivates \\
you to \\
properly \\
perform the \\
task? (time, \\
payment, \\
recognition, \\
quality of life \\
at work) \\
\end{tabular} & $\begin{array}{l}\text { Do you } \\
\text { need to } \\
\text { perform } \\
\text { the task } \\
\text { or is it } \\
\text { automatic } \\
\text { ? (yes/no) } \\
\\
\end{array}$ \\
\hline 1 & & & & & \\
\hline 2 & & & & & \\
\hline 3 & & & & & \\
\hline 4 & & & & & \\
\hline
\end{tabular}

Figure 2 - Card presented to interviewees to identify factors that affect the performance of the commissions' activities. Source: the authors themselves.

Interviews were recorded, transcribed, and analyzed. For content analysis (Bardin, 1977), the relevant excerpts from the transcriptions were coded and classified in charts as exemplified in Chart 2.

Chart 2 - Content analysis of the interviews - overview of the chart used to analyze the interviews with CAF, CFT, DP, and COMEL.

\begin{tabular}{|cc|}
\hline CoM-B category & $\begin{array}{c}\text { Description of the factor that leads to the poor } \\
\text { performance of 'x' commission }\end{array}$ \\
\hline Physical capability & \begin{tabular}{c} 
Not mentioned by the interviewee \\
\hline Psychological capability \\
Not mentioned by the interviewee
\end{tabular} \\
\hline Physical opportunity & $\begin{array}{c}\text { - Lack of personnel. } \\
\text { of personnel }\end{array}$ \\
\hline Social opportunity & $(\ldots)$ \\
\hline Reflective motivation & $($...) \\
\hline Automatic motivation & $\begin{array}{c}\text { - Greatness and relevance of the job. There is no } \\
\text { glamour, so motivation lies in employees' belief in their } \\
\text { work and in their desire to have the best performance. }\end{array}$ \\
\hline
\end{tabular}

Source: the authors themselves.

Next, interviewees' responses were classified into 18 categories to allow for quantitative analysis of interviews (Chart 3), namely:

Chart 3 - Classification categories identified during the content analysis of interviews

\begin{tabular}{|cc|}
\hline 1. Professional training & 10. Inappropriate ergonomic conditions \\
\hline 2. Lack of professional experience & 11. Unnecessary processes \\
\hline 3. Lack of computerization & 12. Insufficient human resources \\
\hline 4. Limited physical space & 13. Adverse social conditions in the work environment \\
\hline 5. Lack of team commitment & 14. Employee turnover \\
\hline 6. Social relevance of the job & 15. High intern turnover \\
\hline 7. Financial issues & 16. Legal issues (bidding) \\
\hline 8. Work overload & 17. Legal issues \\
\hline 9. Misuse of human resources & 18. Legal issues (statute) \\
\hline
\end{tabular}

Source: the authors themselves. 
Finally, the compiled data was used to prepare contingency tables in Excel ${ }^{\circledR}$ to quantify the findings. The interpretation was carried out with the help of the project researchers. We present the results in section 4 of this article.

\section{RESULTS AND DISCUSSION}

As mentioned in the Method section, interviews were carried out with the representatives of the commissions that are responsible for the stages of PCPr cycle: CAF, DP, CFT, COMEL and COORAF. Chart 4 summarizes respondents' characteristics.

Chart 4 - Interviewees' characteristics.

\begin{tabular}{|ccccc|}
\hline Commission & Sex & Age in years & $\begin{array}{c}\text { Academic } \\
\text { background }\end{array}$ & $\begin{array}{c}\text { Highest education } \\
\text { degree }\end{array}$ \\
\hline CAF & Female & 42 & Pharmaceutics & Master's degree \\
\hline DP & Female & $42 / 43$ & Nursing & Bachelor's degree \\
\hline DP & Male & 37 & Pharmaceutics & Bachelor's degree \\
\hline DP & Female & 34 & Pharmaceutics & Specialization course \\
\hline DP & Female & 40 & Pharmaceutics & $\begin{array}{c}\text { Specialization course and } \\
\text { Master's degree }\end{array}$ \\
\hline DP & Female & 40 & Pharmaceutics & Specialization course \\
\hline CFT & Female & 38 & Pharmaceutics & Specialization course \\
\hline COMEL & Female & Not declared & Pharmaceutics & Bachelor's degree \\
\hline COORAF & Male & 32 & Pharmaceutics & Specialization course \\
\hline
\end{tabular}

Source: the authors themselves.

\section{Qualitative application of the COM-B with interview data}

From the qualitative analysis (Appendix A) patterns were identified in the interviewees' responses. The only commission with more than one respondent was DP, which is also justified by the larger number of DP. Responses frequently encompassed complaints regarding employees' deviations from their main duties to perform other tasks in different commissions and mainly within the District Pharmacy itself, among other problems.

Other studies have also reported the role of the pharmacist in activities of lower added value, to a 23.8\% extent (Green et al., 2015), 25\% (Curatolo et al., 2014) and 40.3\% (Fisher et al., 2016). Jenkins and Eckel (2012) managed to reduce by $47 \%$ the time spent by the pharmacist in less complex technical activities, increasing the time spent in activities focused on direct patient contact. Given the high amount of time spent doing other activities by pharmacists, the desired behavior in our analysis is the increase in dedication to the core activity of the duty. The qualitative compilation of data into spreadsheets (Appendix A) allowed for quantitative analysis using contingency tables. Such results are presented in the next item.

\section{Quantitative application of COM-B to the data collected from the interviews}

To identify the COM-B layers that hamper desired behaviors (greater dedication to the core activity of the function), it was used a quantitative approach. This analysis can indicate the layers (Capability, Opportunity, Motivation to perform Behavior) that hamper the desired behavior (Michie et al., 2014). Through the content analysis of the interviews 88 problems were identified, which were categorized (Chart 3 ) and then quantified in Table 1. 
Table 1 - Main problems reported, divided by commission.

\begin{tabular}{|c|c|c|c|c|c|c|}
\hline Main problems reported & CAF & CFT & COMEL & COORAF & DP & Total \\
\hline Physical Capability & & & & & 4 & 4 \\
\hline Inadequate ergonomic conditions & & & & & 2 & 2 \\
\hline Work overload & & & & & 2 & 2 \\
\hline Psychological Capability & 3 & & & 1 & 7 & 11 \\
\hline Adverse working environment conditions & & & & & 2 & 2 \\
\hline $\begin{array}{c}\text { Adverse social conditions of the work } \\
\text { environment }\end{array}$ & & & & & 4 & 4 \\
\hline Professional qualification & 2 & & & & & 2 \\
\hline Professional inexperience & 1 & & & & 1 & 2 \\
\hline Work overload & & & & 1 & & 1 \\
\hline Reflective motivation & 3 & 2 & 1 & 2 & & 8 \\
\hline Adverse working environment conditions & & & & 1 & & 1 \\
\hline Lack of team commitment & & & 1 & & & 1 \\
\hline Social relevance of the work done & 3 & 2 & & 1 & & 6 \\
\hline Physical opportunity & 15 & 7 & 5 & 6 & 29 & 62 \\
\hline Adverse working environment conditions & & & & & 2 & 2 \\
\hline Inadequate ergonomic conditions & & & & & 2 & 2 \\
\hline Limited physical space & 1 & & & & 6 & 7 \\
\hline Professional qualification & 1 & & 1 & & & 2 \\
\hline Process's problem & 11 & 4 & 3 & 4 & 10 & 32 \\
\hline Insufficient human resources & 1 & 2 & 1 & 1 & 5 & 10 \\
\hline Work overload & 1 & & & & & 1 \\
\hline Underutilization of human resources & & 1 & & 1 & 4 & 6 \\
\hline Social opportunity & 1 & & & & 2 & 3 \\
\hline Lack of team commitment & 1 & & & & 1 & 2 \\
\hline Process's problem & & & & & 1 & 1 \\
\hline Total & 22 & 9 & 6 & 9 & 42 & 88 \\
\hline
\end{tabular}

Source: the authors themselves.

To facilitate the visualization of the data above, Table 2 indicates the total number of categories per COM-B layer.

Table 2 - Categories per COM-B layer.

\begin{tabular}{ccc}
\hline COM-B layers & $\mathbf{n}$ & \% \\
\hline Physical Opportunity & 62 & 70.5 \\
\hline Psychological Capability & 11 & 12.5 \\
\hline Reflective Motivation & 8 & 9.1 \\
\hline Physical Capacity & 4 & 4.5 \\
\hline Social Opportunity & 3 & 3.4 \\
\hline Total & $\mathbf{8 8}$ & $\mathbf{1 0 0 . 0}$ \\
\hline
\end{tabular}

Source: the authors themselves. 
Considering the interviewees' opinion in all commissions that develop the operations of the PCPr cycle, there was a predominance of factors that can cause the poor performance in the Physical Opportunity and Psychological Capability categories, comprising $83.0 \%$ of the factors.

As depicted in Table 2, Physical Opportunities comprise $70.5 \%$ of the problems mentioned, which mostly address process's problems, insufficient human resources, and infrastructure as described in Table 3.

Table 3 -Physical Opportunity categories

\begin{tabular}{ccc}
\hline Physical opportunity categories & $\mathbf{n}$ & $\mathbf{\%}$ \\
\hline Process's problem & 32 & 51.61 \\
\hline Insufficient human resources & 10 & 16.13 \\
\hline Limited physical space & 7 & 11.29 \\
\hline Underutilization of human resources & 6 & 9.68 \\
\hline Adverse working environment conditions & 2 & 3.23 \\
\hline Inadequate ergonomic conditions & 2 & 3.23 \\
\hline Professional qualification & 2 & 3.23 \\
\hline Work overload & 1 & 1.61 \\
\hline Total & $\mathbf{6 2}$ & $\mathbf{1 0 0 . 0 0}$ \\
\hline
\end{tabular}

Source: the authors themselves.

The incipient computerization in all commissions leads to 'process problems' and 'work overload', as, several activities that could be automatized are done manually, leading to high human resources and time costs, leading to mistakes.

These categories multiply the obstacles (Michie et al., 2014), as the lack of staff leads to 'underutilization of human resources' and the operational tasks are done by overly qualified workers, as described by the expression 'fancy clerk' mentioned by one of the interviewees concerning his/her activity at DP. In addition to impacting 'work overload', which is a relevant cause of demotivation.

Poor infrastructure is also perceived as causing other problems. It generates 'process's problems', 'adverse working environment conditions' and 'inadequate ergonomic conditions', which are also factors that strongly influence employee demotivation.

Thus, Physical Opportunity influences the other layers of COM-B, such as the Psychological Motivation, as described earlier, and Psychological Capability, as the respondents reported that the 'heavy workload' and 'poor infrastructure' cause lack of attention and fatigue. This permeability between the layers of the COM-B is an important feature to be considered when choosing the intervention, as correction of 'Physical Opportunity' faults increases 'Motivation' and 'Psychological capability', reinforcing the adherence to the desired behavior.

Thus, to achieve the desired behavior - i.e. that workers focus on their own tasks - the 'Physical Opportunity' must be changed. Additionally, given the interaction among COM-B layers, by optimizing the 'Physical Opportunity', the 'Motivation' and 'Psychological Capability' should also be positively affected. Therefore, given this result and the results described in Table 4, solving the 'Physical Opportunity' could resolve at least $94 \%$ of the problems described. 
Table 4 - Percentage of categories separated by commission and their cumulative percentage.

\begin{tabular}{|c|c|c|c|c|c|c|c|c|c|}
\hline & Category & CAF & CFT & COMEL & COORAF & DP & $\mathbf{n}$ & $\%$ & Cumulative \\
\hline \multirow{13}{*}{ 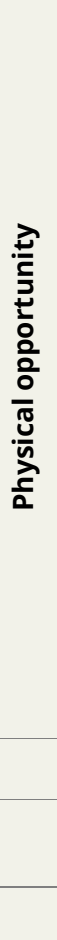 } & Process problem & 11 & 4 & 3 & 4 & 11 & 33 & $38 \%$ & $38 \%$ \\
\hline & Insufficient human resources & 1 & 2 & 1 & 1 & 5 & 10 & $11 \%$ & $49 \%$ \\
\hline & Limited physical space & 1 & & & & 6 & 7 & $8 \%$ & $57 \%$ \\
\hline & $\begin{array}{l}\text { Social relevance of the work } \\
\text { done }\end{array}$ & 3 & 2 & & 1 & & 6 & $7 \%$ & $64 \%$ \\
\hline & $\begin{array}{l}\text { Underutilization of human } \\
\text { resources }\end{array}$ & & 1 & & 1 & 4 & 6 & $7 \%$ & $70 \%$ \\
\hline & $\begin{array}{l}\text { Adverse working } \\
\text { environment conditions }\end{array}$ & & & & 1 & 4 & 5 & $6 \%$ & $76 \%$ \\
\hline & $\begin{array}{l}\text { Inadequate ergonomic } \\
\text { conditions }\end{array}$ & & & & & 4 & 4 & $5 \%$ & $81 \%$ \\
\hline & $\begin{array}{l}\text { Adverse social conditions to } \\
\text { the work environment }\end{array}$ & & & & & 4 & 4 & $5 \%$ & $85 \%$ \\
\hline & Professional qualification & 3 & & 1 & & & 4 & $5 \%$ & $90 \%$ \\
\hline & Work overload & 1 & & & 1 & 2 & 4 & $5 \%$ & $94 \%$ \\
\hline & Lack of team commitment & 1 & & 1 & & 1 & 3 & $3 \%$ & $98 \%$ \\
\hline & $\begin{array}{l}\text { Lack of professional } \\
\text { experience }\end{array}$ & 1 & & & & 1 & 2 & $2 \%$ & $100 \%$ \\
\hline & Total & 22 & 9 & 6 & 9 & 42 & 88 & $100 \%$ & - \\
\hline
\end{tabular}

Source: the authors themselves.

In the individual analysis segmented per commission, even though the Physical Opportunity is the main barrier to reach the desired behavior, the descriptive analysis shows that it occurs differently in each commission (Table 5). Additionally, it is worth highlighting that DP have more categories than the other commissions as DP had more interviewees and it is responsible for more activities than the other commissions.

Table 5 - Categories per COM-B layer and sector

\begin{tabular}{|c|c|c|c|c|c|c|c|c|c|c|c|c|}
\hline \multirow{2}{*}{ COM-B } & \multicolumn{2}{|c|}{ CAF } & \multicolumn{2}{|c|}{ CFT } & \multicolumn{2}{|c|}{ COMEL } & \multicolumn{2}{|c|}{ COORAF } & \multicolumn{2}{|c|}{ DP } & \multicolumn{2}{|c|}{ Total } \\
\hline & $\mathbf{n}$ & $\%$ & $\mathbf{n}$ & $\%$ & $\mathbf{n}$ & $\%$ & $\mathbf{n}$ & $\%$ & $\mathbf{n}$ & $\%$ & $\mathbf{n}$ & $\%$ \\
\hline Physical opportunity & 15 & 68.18 & 7 & 77.78 & 5 & 83.33 & 6 & 66.67 & 29 & 69.05 & 62 & 70.45 \\
\hline $\begin{array}{l}\text { Psychological } \\
\text { capability }\end{array}$ & 3 & 13.64 & - & 0.00 & - & 0.00 & 1 & 11.11 & 7 & 16.67 & 11 & 12.50 \\
\hline Reflective motivation & 3 & 13.64 & 2 & 22.22 & 1 & 16.67 & 2 & 22.22 & - & 0.00 & 8 & 9.09 \\
\hline Physical capability & - & 0.00 & - & 0.00 & - & 0.00 & - & 0.00 & 4 & 9.52 & 4 & 4.55 \\
\hline Social opportunity & 1 & 4.55 & - & 0.00 & - & 0.00 & - & 0.00 & 2 & 4.76 & 3 & 3.41 \\
\hline Total & 22 & 100.0 & 9 & 100.0 & 6 & 100.0 & 9 & 100.0 & 42 & 100.0 & 88 & 100.0 \\
\hline
\end{tabular}

Source: the authors themselves.

\section{Categories per commission}

The categories identified in each commission are depicted in Chart 5 to facilitate the visualization of the patterns identified in each of the analyzed commissions, considering their specific demands. The specific demands for each commission must be analyzed before 
planning changes. Factors in italics were mentioned by more than one interviewee from the commissions.

Considering the cycle of selection, programming, acquisition, storage, distribution, and dispensing of medicines (SPASDD), CFT is responsible for the selection stage, while COMEL is responsible for medicine acquisition. Interviewees from both commissions highlighted the underutilization of human resources or the lack of staff to perform the tasks needed as factors that hamper their activities. Work overload can be a consequence of the lack of personnel and an alternative would be data digitalization, which mitigates the problem. Interviewees did not mention factors in the 'Social opportunity' and 'Physical or psychological capability' categories, which suggests that they do not feel affected in these aspects. However, the lack of 'Physical opportunity' mentioned above can affect 'reflective motivation', which was also mentioned in both commissions.

It is important to highlight that, for employees, CFT is an additional task to other functions since CFT's committee is composed of professionals originally from other areas. The lack of physical resources and the need to dedicate to more tasks lead to work overload, as described by the interviewee: "(...) Employees are not paid to join the commission, so it is one extra activity that must be done in a context of a lack of physical and human resources (CFT interviewee)."

Chart 5- Summary of factors and categories pointed out by the commissions' respondents for the PCPr cycle processes.

\begin{tabular}{|c|c|c|c|c|}
\hline \multicolumn{5}{|c|}{ COM-B layer segmented by commission } \\
\hline CAF & CFT & COMEL & COORAF & DP \\
\hline \multirow[t]{3}{*}{ Physical capability } & Physical capability & $\begin{array}{l}\text { Physical } \\
\text { capability }\end{array}$ & Physical capability & Physical capability \\
\hline & & & & $\begin{array}{l}\text { - Inadequate ergonomic } \\
\text { conditions }\end{array}$ \\
\hline & & & & - Work overload \\
\hline $\begin{array}{l}\text { Psychological } \\
\text { capability }\end{array}$ & $\begin{array}{l}\text { Psychological } \\
\text { capability }\end{array}$ & $\begin{array}{l}\text { Psychologic } \\
\text { al capability }\end{array}$ & $\begin{array}{l}\text { Psychological } \\
\text { capability }\end{array}$ & $\begin{array}{l}\text { Psychological } \\
\text { capability }\end{array}$ \\
\hline $\begin{array}{l}\text { - Professional } \\
\text { qualification }\end{array}$ & & & - Work overload & $\begin{array}{c}\text { - Adverse work } \\
\text { environment conditions }\end{array}$ \\
\hline \multirow[t]{2}{*}{$\begin{array}{l}\text { - Professional } \\
\text { inexperience }\end{array}$} & & & & $\begin{array}{l}\text { - Adverse social } \\
\text { conditions to the work } \\
\text { environment }\end{array}$ \\
\hline & & & & $\begin{array}{l}\text { - Professional } \\
\text { inexperience }\end{array}$ \\
\hline $\begin{array}{l}\text { Reflective } \\
\text { motivation }\end{array}$ & $\begin{array}{l}\text { Reflective } \\
\text { motivation }\end{array}$ & $\begin{array}{l}\text { Reflective } \\
\text { motivation }\end{array}$ & $\begin{array}{l}\text { Reflective } \\
\text { motivation }\end{array}$ & Reflective motivation \\
\hline \multirow[t]{2}{*}{$\begin{array}{l}\text { - Adverse social } \\
\text { conditions to the work } \\
\text { environment }\end{array}$} & $\begin{array}{l}\text {-Adverse social } \\
\text { conditions to the work } \\
\text { environment }\end{array}$ & $\begin{array}{c}\text {-Lack of } \\
\text { team } \\
\text { commitment }\end{array}$ & $\begin{array}{l}\text { - Adverse work } \\
\text { environment } \\
\text { conditions }\end{array}$ & \\
\hline & & & $\begin{array}{l}\text { - Adverse social } \\
\text { conditions to the work } \\
\text { environment }\end{array}$ & \\
\hline Physical opportunity & Physical opportunity & $\begin{array}{c}\text { Physical } \\
\text { opportunity }\end{array}$ & Physical opportunity & Physical opportunity \\
\hline - Limited physical space & - Process Problem & $\begin{array}{l}\text { - Professional } \\
\text { qualification }\end{array}$ & - Process's problem & $\begin{array}{c}\text { - Adverse work } \\
\text { environment conditions }\end{array}$ \\
\hline $\begin{array}{l}\text { - Professional } \\
\text { qualification }\end{array}$ & $\begin{array}{l}\text { - Insufficient human } \\
\text { resources }\end{array}$ & $\begin{array}{l}\text { - Process } \\
\text { problem }\end{array}$ & $\begin{array}{l}\text { - Insufficient human } \\
\text { resources }\end{array}$ & $\begin{array}{l}\text { - Inadequate ergonomic } \\
\text { conditions }\end{array}$ \\
\hline - Process problem & $\begin{array}{l}\text { - Underutilization of } \\
\text { human resources }\end{array}$ & $\begin{array}{l}\text { - Insufficient } \\
\text { human } \\
\text { resources }\end{array}$ & $\begin{array}{l}\text { - Underutilization of } \\
\text { human resources }\end{array}$ & - Limited physical space \\
\hline
\end{tabular}


Application of COM-B model as a support to Lean Healthcare diagnostic: the case of Pharmaceutical Care Process

Chart 5- Continued...

\begin{tabular}{|c|c|c|c|c|}
\hline \multicolumn{5}{|c|}{ COM-B layer segmented by commission } \\
\hline CAF & CFT & COMEL & COORAF & DP \\
\hline $\begin{array}{l}\text { - Insufficient human } \\
\text { resources }\end{array}$ & & & & - Process problem \\
\hline \multirow[t]{2}{*}{ - Work overload } & & & & $\begin{array}{l}\text { - Insufficient human } \\
\text { resources }\end{array}$ \\
\hline & & & & $\begin{array}{l}\text { - Underutilization of } \\
\text { human resources }\end{array}$ \\
\hline Social opportunity & Social opportunity & $\begin{array}{c}\text { Social } \\
\text { opportunity }\end{array}$ & Social opportunity & Social opportunity \\
\hline $\begin{array}{l}\text { - Lack of team } \\
\text { commitment }\end{array}$ & & & & $\begin{array}{c}\text { - Lack of team } \\
\text { commitment } \\
\text { - Process problem }\end{array}$ \\
\hline 22 & 9 & 6 & 9 & 42 \\
\hline
\end{tabular}

Source: the authors themselves.

The review of CFT and COMEL processes can be an opportunity for improvement, by reducing 'process's problems', as well as better using the human resources involved. Digitalization of processes, as suggested, without reviewing current processes, would only accelerate possibly unnecessary and inefficient processes.

The factors pointed out by CAF and DP respondents were grouped into three categories that did not appear in the CFT and COMEL interviews: "Physical capacity" and "Psychological capacity".

CAF's function is to store and distribute medicines to the 10 DP and 139 Health Units in the city of Porto Alegre. The DP and the Health Units store and distribute medicines for citizens. Many of the activities carried out in these sectors are conducted with the support of interns. CAF also hires lower-educated employees to support logistical activities. In both cases, there is the issue of professional inexperience or knowledge limitations for the task, affecting the responsibility of the leaders, who feel obliged to supervise the tasks more intensely or, in more extreme cases, perform the tasks. In these cases, the factor 'lack of team commitment' caused by work absences was mentioned.

Regarding DP, in addition to the pressure caused by poor physical and ergonomic conditions, there is tension and pressure, due to patients' complaints. This hampers employees' concentration, attention to the prescriptions, and calculations. The psychological exhaustion resulting from these factors compromises attention. The risks also center on the relationship with patients who become aggressive, even threatening employees, affecting the psychological health of the whole team. The "Psychological capability", which generates Motivation, is compromised as described by the interviewees:

“(...) what discourages us is the fact that we are unable to provide the best care, not having a team of reasonable size, or the necessary medication to provide to the person. Fights and noise are also demotivating, as people start talking and talking loudly in line (DP interviewee).

The 'Reflective motivation' is of easier understanding and was mentioned by all the interviewees, except for the DP's. Every interviewee recognized the 'social relevance of the work done in the PCPr' that distributes medicines directly to the population. Such a fact may lead employees to face the restrictions with persistence, overcoming the limitations of the inadequate physical and ergonomic conditions. This effort's main damage may be the psychological component, as pointed out by interviewees from the COORAF, DP, and CAF.

In general, the application of COM-B helped in the identification of improvement opportunities, but special attention should be paid to the existence of unnecessary processes, as interviewees mentioned (Emiliani, 1998). 
“(...) the need to demand other committee members to do the tasks that have already been delegated. (...) Unnecessary processes such as having to send a reminder for the person to perform the task they already knew they should do and this dependence on other sectors to advance activities (COMEL interviewee)".

“(...) Patients could bring the prescriptions with the data already filled in to speed up the process (DP interviewee)".

Losses are a constant target of Lean Healthcare. Eliminating unnecessary processes that do not add value to users of the entire cycle and to the patients of the network is essential and a great opportunity for Lean implementation practices. Not only losses due to unnecessary processes, but also those due to unnecessary movement (Sawhney and Chason, 2005). The following quote reflects the need for patient or pharmacist motion due to prescription problems that do not meet the requirements caused by doctors. This problem causes anger and inconvenience to the patients which cause psychological problems in pharmacists and DP employees. "(...) Doctors do not meet the requirements of the prescription, such as signature and date, making care unfeasible, which makes patients angry (DP interviewee)".

Rework also reflects a material loss, as shown below."(...) Lots with very similar numbers cause more confusion at the inspection".

Other storage losses can be eliminated from the cycle. Proper acquisition scheduling could reduce the size of purchased volumes, also, risks of mistakes arising from the lack of storage space and the lack of computerization were mentioned, especially in the DP and CAF. “(...) Insufficient space to separate lots; (...) Manual activities that could be computerized, avoiding many human mistakes (CAF interviewee).

The evidence presented earlier confirms the hypothesis that the COM-B tool can be used as an instrument to identify inefficient behaviors in the context of Lean Healthcare. COM-B not only allowed identifying behaviors to be changed with the help of the Behavior Change Wheel (BCW), such as demotivation, lack of commitment, tension, physical and psychological tiredness, but also allowed the identification of wastes that are opportunities for Lean Healthcare implementation practices.

The relationship between behavior, physical and psychological capabilities, and social and physical opportunities for employee motivation is a direction that will guide the organization of work and processes in the stages of the SPASDD cycle. Considering that the Lean Healthcare implementation starts at a diagnostic and provided that COM-B model allowed the identification of behaviors to be changed, in order of making the PCPr flows to perform better. The next steps would be the application of other BCW levels as well as, Lean Healthcare practices and tools for reduction of process losses and process optimization.

\section{Future application of the COM-B in the BCW}

As this study validated the applicability of the COM-B model to identify the factors that lead to inefficiency, it is worth mentioning an example of the application of COM-B in its original function. After identification of behaviors to be changed we should proceed to the next levels of the BCW, namely, the intervention functions and political categories, as described in the example below.

In the case of the professionalization of the team, the desired behavior ' $\mathrm{B}$ ' is employees' qualification. Employees have physical and psychological capabilities to professionalize themselves, however, they do not have physical and social opportunities or even motivation. As we have identified, these impediments are related to Physical and social opportunity and Motivation. Therefore, it is necessary to choose the intervention functions that lead to qualification. Education, Persuasion, Incentive and Environment Restructuring would be interesting alternatives to support professionalization. After choosing the intervention functions, the next step (the last level of the BCWheel) addresses the political categories. Communication and Social Planning would be ideal aspects to promote professional qualifications. 
Although this was a single example, other rationale could be applied in the case studied. Thus, as our results demonstrated, the COM-B model may be used to design future interventions in PCPr in Porto Alegre. The conjoint application of other levels of BCW and Lean Healthcare practices would be natural future investigations.

\section{FINAL CONSIDERATIONS}

As our data analysis showed, the COM-B model can be used in the change management process to identify inefficient behaviors that must be reconsidered to achieve the efficiency sought by the Lean Healthcare diagnosis methodology. Additionally, the COM-B model can be used to identify the factors in terms of Capability, Opportunity, and Motivation that must be changed to achieve the behavior identified as efficient by the COM-B model.

Regarding COM-B contribution, the instrument proved to be a useful tool for identifying inefficient behaviors, as it replaced the more complex methodology of BCW for such identification, which demands a greater number of longer interviews.

The tool also proved to be very useful in practice, since it identified the desired behavior, as well as the actions that must be taken to achieve it. A research limitation can be the reduced number of respondents. However, the data from the interviews was enough to capture the perceptions and build a scenario that could be validated in the future with the other stakeholders involved in the process.

\section{ACKNOWLEDGMENTS}

We would like to thank the interviewees, the COORAF, represented by Leonel Almeida and pharmacists, for the openness and continuous contribution to this project, and the project participants for helping in the discussion of the results.

\section{REFERENCES}

Bardin, L. (1977), Content Analysis, Editions 70, Lisboa.

Barker, F., Atkins, L. and de Lusignan, S. (2016), "Applying the COM-B behaviour model and behaviour change wheel to develop an intervention to improve hearing-aid use in adult auditory rehabilitation", International Journal of Audiology, Vol. 55, Suppl. 3, pp. S90-8.

Biazzo, S. and Panizzolo, R. (2000), "The assessment of work organization in Lean production: the relevance of the worker's perspective", Integrated Manufacturing Systems, Vol. 11, No. 1, pp. 6-15.

Brazil, Ministry of Health, Science Secretariat, Technology and Strategic Inputs, Pharmaceutical Assistance and Strategic Inputs Department (2014), Pharmaceutical Services in Primary Health Care, Ministry of Health, Brasília, DF.

Costa, L.B.M., Godinho Filho, M.G., Rentes, A.F. et al. (2017), "Lean healthcare in developing countries: evidence from Brazilian hospitals", The International Journal of Health Planning and Management, Vol. 32, No. 1, pp. e99-120.

Curatolo, N., Vercaeren, S., Wright, P. et al. (2014), "Clinical pharmacy services in cardiology: a lean perspective analysis", European Journal of Hospital Pharmacy. Science and Practice, Vol. 21, Suppl. 1, pp. A116-7.

Drew, J., McCallum, B. and Roggenhofer, S. (2004), Journey to Lean: Making Operational Change Stick, Palgrave Macmillan, New York.

Emiliani, M.L. (1998), "Lean behaviours", Management Decision, Vol. 36, No. 9, pp. 615-31.

Fisher, A.M., Ding, M.Q., Hochheiser, H. et al. (2016), "Measuring time utilization of pharmacists in the Birmingham Free Clinic dispensary", BMC Health Services Research, Vol. 16, No. 1, pp. 529.

Furukawa, P.O., Cunha, I.C.K.O. and Pedreira, M.L.G. (2016), "Evaluation of environmentally sustainable actions in the medication process", Revista Brasileira de Enfermagem, Vol. 69, No. 1, pp. 23-9.

Graban, M. (2009), Lean Hospitals, CRC, New York. 
Green, C.F., Crawford, V., Bresnen, G. et al. (2015), "A waste walk through clinical pharmacy: how do the "seven wastes" of Lean techniques apply to the practice of clinical pharmacists", International Journal of Pharmacy Practice, Vol. 23, No. 1, pp. 21-6.

Instituto Brasileiro de Geografia e Estatística, Portal Cidade, 2018. https://www.ibge.gov.br/cidades-eestados/rs/porto-alegre.html. Acesso em: 25/09/2020.

Jenkins, A. and Eckel, S.F. (2012), "Analyzing methods for improved management of workflow in an outpatient pharmacy setting", American Journal of Health-System Pharmacy, Vol. 69, No. 11, pp. 96671.

Michie, S., Atkins, L. and West, R. (2014), The Behaviour Change Wheel: A Guide to Designing Interventions, Silverback Publishing, Great Britain.

Michie, S., Atkins, L. and Gainforth, H. (2016), Changing Behaviour to Improve Clinical Practice and Policy, Department of Clinical, Educational and Health Psychology, University College London, London, available at: https://www.researchgate.net/publication/311857816_Changing_Behaviour_to_Improve_Clinical_Pr actice_and_Policy (accessed 2 July 2020).

Niedderer, K., Cain, R., Clune, S. et al. (2014), Creating Sustainable Innovation Through Design for Behaviour Change: Full Project Report, Loughborough University Institutional Repository, London, available at: https://dspace.lboro.ac.uk/dspace-jspui/bitstream/2134/17410/1/PUB\%20LDS\%20920\%20AHRCDesign-for-Behaviour-Change-Full-Report.pdf (accessed 2 July 2020).

Norman, D.A. (1988), The Psychology of Everyday Things, MIT Press, Cambridge.

Sawhney, R. and Chason, S. (2005), "Human behaviour based exploratory model for successful implementation of lean enterprise in industry", Performance Improvement Quarterly, Vol. 18, No. 2, pp. 76-96.

Simon, H.A. (1969), The Science of the Artefact, MIT Press, Cambridge.

Author contributions: Karina Yamashiro Barrionuevo: Data collection and writing.Istefani Carísio de Paula: Supervisor and Project manager - *Corresponding author. Aline Cafruni Gularte: data analysis. Lúcia Sortica de Bittencourt: data collection and analysis support 
APPENDIX A. INTERVIEWS' CONTENT ANALYSIS.

\begin{tabular}{|c|c|}
\hline COM-B layers & $\begin{array}{l}\text { Description of the content that causes poor performance of } \\
\text { the Pharmaceutical Supply Center - CAF }\end{array}$ \\
\hline Physical capability & - \\
\hline \multirow[t]{3}{*}{ Psychological capability } & Lack of training and/or professional experience \\
\hline & $\begin{array}{l}\text { Majority of the team lacks academic education and knowledge in } \\
\text { warehousing, and medication and batch control. }\end{array}$ \\
\hline & Many employees had never worked before (first job). \\
\hline \multirow[t]{3}{*}{ Reflective motivation } & $\begin{array}{l}\text { The team is motivated when they are reminded of the importance } \\
\text { of the work they execute, as there is an impact on one and a half } \\
\text { million people. }\end{array}$ \\
\hline & Employees work even when they are not receiving salary. \\
\hline & Social relevance of work and health \\
\hline Automatic motivation & - \\
\hline \multirow[t]{15}{*}{ Physical opportunity } & High turnover \\
\hline & Inappropriate carts for storage operations \\
\hline & Insufficient space to carry out the separation of the batches; \\
\hline & Lack of space for employees' rest \\
\hline & $\begin{array}{l}\text { Lack of computerization, as employees reported feeling } \\
\text { overworked. }\end{array}$ \\
\hline & Lack of training \\
\hline & Lack of barcodes \\
\hline & Pharmacists sorting orders and storing boxes \\
\hline & $\begin{array}{l}\text { Employees do not receive PPE (Personal Protective Equipment) } \\
\text { and uniforms }\end{array}$ \\
\hline & $\begin{array}{l}\text { Incipient and scarce computerization; Manual activities could be } \\
\text { computerized, avoiding many human errors; }\end{array}$ \\
\hline & Lots with very similar numbers. \\
\hline & No labor gymnastics \\
\hline & No food stamps \\
\hline & Employees could use a hand gadget to record medicines receipts \\
\hline & Late wage payment \\
\hline Social opportunity & Lack of team commitment \\
\hline
\end{tabular}




\begin{tabular}{|c|c|}
\hline COM-B layers & $\begin{array}{l}\text { Description of the factors that cause poor performance of the District } \\
\text { Pharmacies - DP }\end{array}$ \\
\hline \multirow[t]{3}{*}{ Physical capability } & Physical and psychological tiredness \\
\hline & Physical tiredness impairs attention \\
\hline & $\begin{array}{c}\text { Difficulty of dragging heavy chairs in a small environment. It disturbs the } \\
\text { environment. }\end{array}$ \\
\hline \multirow[t]{7}{*}{$\begin{array}{l}\text { Psychological } \\
\text { capability }\end{array}$} & $\begin{array}{l}\text { The team is motivated by helping people. What is discouraging, however, is } \\
\text { the fact that they cannot provide the best care, do not have a team of } \\
\text { reasonable size, do not have the medication to offer to the person. Fights } \\
\text { and noise are also demotivating, as people start talking and talking loudly in } \\
\text { line. }\end{array}$ \\
\hline & $\begin{array}{l}\text { Some patients are aggressive and even threaten employees, affecting the } \\
\text { entire team's psychological healthiness. }\end{array}$ \\
\hline & Physical and psychological tiredness \\
\hline & Psychological tiredness compromises attention. \\
\hline & New interns with incipient knowledge. \\
\hline & $\begin{array}{l}\text { Pressure from patients, many are impolite and cause inconvenience, } \\
\text { affecting employees' psychological healthiness. }\end{array}$ \\
\hline & $\begin{array}{l}\text { Tension, pressure, patients' complaints that disturb employees' } \\
\text { concentration, and the attention on the prescriptions and calculations. }\end{array}$ \\
\hline \multirow[t]{17}{*}{$\begin{array}{l}\text { Physical } \\
\text { opportunity }\end{array}$} & $\begin{array}{l}\text { The team is motivated by helping people. What is discouraging, however, is } \\
\text { the fact that they cannot provide the best care, do not have a team of } \\
\text { reasonable size, do not have the medication to offer to the person. Fights and } \\
\text { noise are also demotivating, as people start talking and talking loudly in line. }\end{array}$ \\
\hline & $\begin{array}{l}\text { The chairs are old and are not suitable for counter service, a task that } \\
\text { requires several movements. }\end{array}$ \\
\hline & $\begin{array}{l}\text { Time-consuming activities: counting prescriptions, organizing patient line } \\
\text { order, and loading boxes. }\end{array}$ \\
\hline & $\begin{array}{l}\text { As human resources are below what is necessary, interns act as a workforce } \\
\text { while they should do more productive activities. There is no time for } \\
\text { professionals to guide trainees in a qualified way because they also suffer from } \\
\text { work overload, being diverted to tasks such as counter service, supplying } \\
\text { medications, temperature measurement, stock counting. }\end{array}$ \\
\hline & $\begin{array}{l}\text { The system counts the number of drugs dispensed and patients attended, } \\
\text { but not the number of prescriptions. }\end{array}$ \\
\hline & It takes time to hire interns since turnover is high. \\
\hline & $\begin{array}{c}\text { Difficulty dragging heavy chairs in a small environment. It disturbs the } \\
\text { environment. }\end{array}$ \\
\hline & Inadequate equipment and ergonomics, which make employees tired. \\
\hline & Insufficient space in the pharmaceutical room and for storage. \\
\hline & Insufficient space for the medication check. \\
\hline & Stock not located in the pharmacy, which hampers difficult. \\
\hline & Pharmacy structure and location. \\
\hline & Lack of interconnection between ordering and receiving medicines. \\
\hline & Insufficient counters. More counters should be built. \\
\hline & Need to copy the prescription. \\
\hline & $\begin{array}{l}\text { Patients could bring forms already filled out to make the process faster. } \\
\text { Doctors do not meet the requirements of the prescription such as signature } \\
\text { and date, making it impossible to deliver the medicines, which makes } \\
\text { patients angry. }\end{array}$ \\
\hline & Filling out prescriptions delays tasks. \\
\hline & Unnecessary processes for bureaucratic issues \\
\hline
\end{tabular}




\begin{tabular}{|c|c|}
\hline COM-B layers & $\begin{array}{l}\text { Description of the factors that cause poor performance of the District } \\
\text { Pharmacies - DP }\end{array}$ \\
\hline & $\begin{array}{l}\text { Incomplete staff to occupy the booths during the eight hours. Then } \\
\text { professionals must stop performing their activities to serve patients. }\end{array}$ \\
\hline & Greater qualification of suppliers to avoid delivery delays at the supply center. \\
\hline & Insufficient human resources to meet the demand. \\
\hline & $\begin{array}{l}\text { Insufficient human resources to perform tasks that take time, such as } \\
\text { checking and replacing medications, refilling the inventory, feeding bins. }\end{array}$ \\
\hline & Human Resources sector is underutilized. \\
\hline & $\begin{array}{l}\text { In the DP, the air conditioning equipment was stolen. The city hall } \\
\text { administration has bought new equipment, but there is no staff to install it. }\end{array}$ \\
\hline \multirow[t]{2}{*}{ Social Opportunity } & The non-replacement of vacant positions discourages the team. \\
\hline & Lack of employee commitment, such as absences. \\
\hline
\end{tabular}

\begin{tabular}{|c|c|}
\hline COM-B layers & $\begin{array}{c}\text { Description of the factors that lead to poor performance of the } \\
\text { Therapeutic Pharmacy Commission - CFT }\end{array}$ \\
\hline \multirow[t]{2}{*}{ Reflective motivation } & $\begin{array}{l}\text { Greatness and relevance of the work. There is no glamor, motivation } \\
\text { relies on employees' belief in the work executed and wanting to do it } \\
\text { in the best way. }\end{array}$ \\
\hline & Social relevance of the work \\
\hline \multicolumn{2}{|l|}{ Automatic motivation } \\
\hline \multirow[t]{6}{*}{ Physical opportunity } & 'Fancy clerk' - pharmacists serve patients due to lack of staff. \\
\hline & Lack of employees \\
\hline & Lack of computerization \\
\hline & Lack of motivation for not having remuneration \\
\hline & $\begin{array}{l}\text { There are no records/minutes of meetings that deal with solutions for } \\
\text { unnecessary losses. }\end{array}$ \\
\hline & $\begin{array}{l}\text { Need for meetings to create a report on a certain drug. Without this } \\
\text { report, prices cannot be registered }\end{array}$ \\
\hline Social opportunity & - \\
\hline Physical capability & - \\
\hline Psychological capability & - \\
\hline
\end{tabular}

\begin{tabular}{|c|c|}
\hline COM-B layers & $\begin{array}{l}\text { Description of the factors that lead to poor performance on the } \\
\text { Commission for the Evaluation of Medicines in Bidding Process - } \\
\text { COMEL }\end{array}$ \\
\hline Reflective motivation & Need for supervising caused by the lack of employee commitment \\
\hline Automatic motivation & - \\
\hline \multirow[t]{5}{*}{ Physical opportunity } & $\begin{array}{c}\text { Multiple tasks focused on one employee due to lack of human } \\
\text { resources }\end{array}$ \\
\hline & Multiple tasks or overload \\
\hline & Human resources qualification issues \\
\hline & Unnecessary processes \\
\hline & Bureaucratic issues related to the quality of inputs and delivery \\
\hline Social opportunity & - \\
\hline Physical capability & - \\
\hline Psychological capability & - \\
\hline
\end{tabular}




\begin{tabular}{|cc|}
\hline COM-B layers & $\begin{array}{c}\text { Description of the factors that lead to poor performance in the } \\
\text { Pharmaceutical Care Coordination - COORAF }\end{array}$ \\
\hline Psychological capability & It is humanly almost impossible to execute so many tasks \\
\hline Physical capability & - \\
\hline Reflective motivation & Employees feel under pressure \\
\hline Automatic motivation & Concern about " stopping the wheel " \\
\hline Physical opportunity & Lack of space \\
\hline & Lack of computerization \\
\hline & Lack of human resources \\
\hline & There is a lack of knowledge about a particular tool \\
\hline & Lack of tools to deliver ready-to-use data \\
\hline Social opportunity & Poor use of human resources \\
\hline
\end{tabular}

